\title{
Simulation and Analysis of Protection Issues in Distributed Generation Integrated Systems using Artificial Intelligent Controllers
}

\author{
Santosh Kumar Vishwakarma, E. Vijay Kumar
}

\begin{abstract}
In this paper, protection issues that arise due to distributed generation when integrated in the system are discussed. Protection of distribution system with the incidence of distributed generation can be achieved by designing the intelligent controllers that operate both under normal and faulted conditions. To analyze the issues related to protection and the performance of various distributed resources like wind turbines, microturbines, solar, PEMFC and SOFC units are considered in this paper. They are designed and modelled in MATLABSIMULINK environment. The wind power in this model is driven by an induction machine. To analyze deeply the performance of various distributed resources impact under normal and fault conditions a study has been done by simulating the various Artificial Intelligent Controllers. It can be seen from the simulation results that the performance of the DG units under normal and fault conditions is good with the AI controllers like Fuzzy, model reference adaptive controller compared to that of the conventional PID controller.
\end{abstract}

Index Terms: Distributed Generation, DSTATCOM, Power quality issues, Non-linear loads.

\section{INTRODUCTION}

In the present world scenario, the major challenges it is facing are protection of the environment, conservation of the existing energy resources and lastly the development of sustainable energy resources.[1]. To combine all of them the main issue is to provide sufficient energy for the customer to utilize without depleting the existing resources rapidly and do it in such a way that the environment is safe. The utilization of the Distributed Generation for the electrical energy production is the new era. The use of the small generating units DG are where usually the rating is less than 10 MW. They are connected to the transmission or distribution systems. The new and latest technologies such as fuel cells, wind energy, micro hydro power sources and solar photovoltaic's makes DG more and more economical and popular [2]-[6].

The Distributed Generation provided the most economical solution for the increasing energy needs. The growth in load and due to its impacts such as overload or low voltage is expected to be obtained by simulating the DG in different

Revised Manuscript Received on July 05, 2020.

* Correspondence Author

Mr. Santosh Kumar Vishwakarma*, Ph.D Scholar, SRK University, Bhopal, India. ndia.

Dr. E. Vijay Kumar, Professor \& HOD/EEE, SRK University, Bhopal,

(C) The Authors. Published by Blue Eyes Intelligence Engineering and Sciences Publication (BEIESP). This is an open access article under the CC BY-NC-ND license (http://creativecommons.org/licenses/by-nc-nd/4.0/) weak and strong locations. There are many series of problems with DGs right from its placement in different location. The necessary control that are required to mitigate the problems of voltage drop created by them is another concern. According to the literature, the DG should be able to be a minimal cost solution for the power optimization problem and ensure the required voltage level under all operating conditions. The DGs that are placed in the system may cater to drastic improvements in terms of reliability and reduce losses of the overall electrical power system. The penetration of the DG into the distribution system leads into a different level of fault current and impedance. This creates various problems in the power protection system, such as protective devices false tripping, protection blinding, a short circuit levels increase and decrease, undesirable network islanding and out of synchronism reclosers.[7]

\section{PROTECTION ISSUES WITH DG}

The existing network distributed systems are planned as passive networks which usually has unidirectional power flow from the central generating station downstream to the consumer loads, i.e. from high voltage level to medium or low voltage levels. Also, the existing protection system configuration is designed as common that the various levels of voltage expect for their ratings as there is no local generation expected throughout the network [7] With the introduction of the distributed resources, the network became active and hence the conventional protection system become unsuitable for the present scenario.

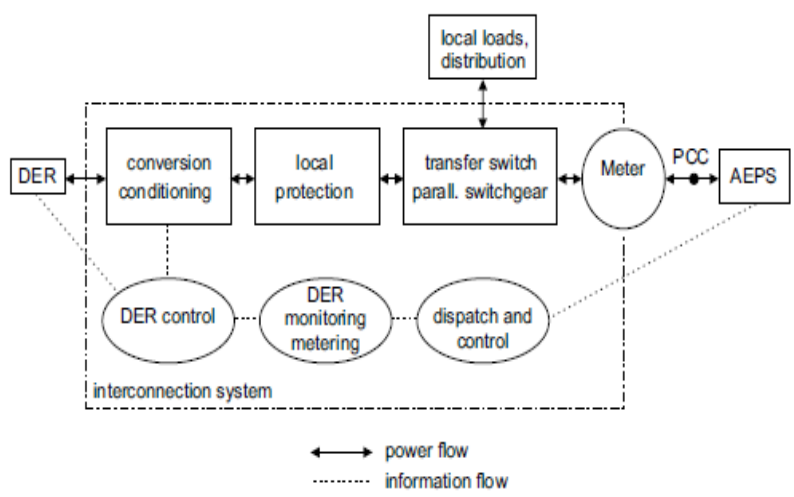

Fig 1: Block Diagram of Distribution system

The distribution generations are more concentrated in some areas of the distribution system, and they are also coupled to various buses as shown in figure 1 . The analysis says that the distributed generations with same control modes which have same functionality

Published By:

Blue Eyes Intelligence Engineering

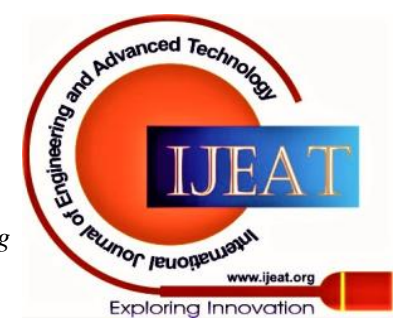


can be modelled as equivalent to the sources in the system considered. The impact of the distribution network with this equivalence is analyzed by having microgrid. The overall distributed generators pertaining to a control are can be viewed as a larger generator with the cumulative capacity, i.e. with the added rating of all the small DG units.

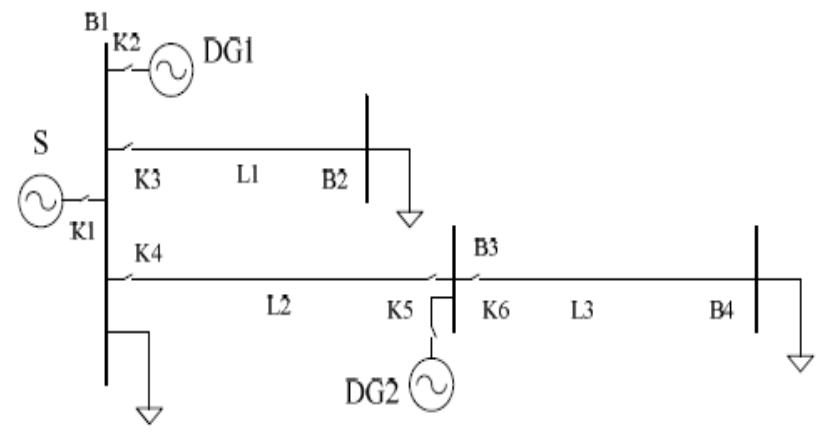

Fig 2: Grid-connected system

The system generally operates at source side at the grid-connection mode normal state network which consists of the distribution resources that can also add up to relative parameters like stable basic voltage and frequency. So, the VF control generators can choose to supply the power even though it is little or can also opt out. Whereas when the micro-grid operates in island mode, the VF control generators have the responsibility of keeping the power balances in the island, thereby compensating the power loss. After the connected island is to use in distribution network, the units which are used for energy storage purpose (usually $\mathrm{VF}$ control generators) need to be recharged. Also, the control of VF generators changes with the load as far as the energy storage equipment is fully charged.

\section{UTILITY REQUIRED PROTECTION}

The solutions that are available for protection are both simple and intricate. The best feasible solution to a problem is always complied to a set of constraints so as to meet the regulatory standards. There are a set of regulations that are required to be followed by the Distributed Generation utilities. Few such areas are mentioned below

- The winding requirements of the grid connecting transformer.

- Suitable Relay configurations for interconnection to the utility

- $\quad$ CT and PT configurations.

- $\quad$ Protection standards complying to 810/U along with $27 \& 59$.

- Fast acting devices present in DG and grid interconnections.

Table 1: Different Transformer connections and their advantages and problems

\begin{tabular}{|c|c|c|c|}
\hline Low Voltage (LV) & High Voltage (HV) & Problems & Advantages \\
\hline Delta & Delta & \multirow{3}{*}{$\begin{array}{l}\text { Can supply the feeder circuit } \\
\text { from an ungrounded source } \\
\text { after substation breaker 'A' trips } \\
\text { causing overvoltage }\end{array}$} & \multirow{3}{*}{$\begin{array}{l}\text { Provide no ground fault back-feed } \\
\text { for fault at F1 \& F2. } \\
\text { No ground current from breaker A } \\
\text { for a fault at F3 }\end{array}$} \\
\hline Gnd-Wye & Delta & & \\
\hline Delta & Wye & & \\
\hline Delta & Gnd-Wye & $\begin{array}{l}\text { Provides an unwanted ground } \\
\text { current for supply circuit faults } \\
\text { at F1 and F2 }\end{array}$ & $\begin{array}{l}\text { No ground current from breaker A } \\
\text { for faults at } F 3 \text {. } \\
\text { No overvoltage for ground fault at } \\
\text { F1 }\end{array}$ \\
\hline Gnd-Wye & Gnd-Wye & $\begin{array}{l}\text { Allows source feeder relaying at } \\
\text { A to respond to a secondary } \\
\text { ground fault at } \mathrm{F} 3\end{array}$ & $\begin{array}{l}\text { No overvoltage for ground fault if } \\
\text { the gen neutral is } Y \text {-connected with } \\
\text { a low impedance ground }\end{array}$ \\
\hline
\end{tabular}
voltage

\begin{tabular}{|l|l|l|}
\hline $\begin{array}{l}\text { System Voltage (kV) - } \\
\text { Secondary }\end{array}$ & Generation Size & $\begin{array}{l}\text { Preferred Interface Transformer } \\
\text { High voltage side : Low voltage side } \\
\text { (HVS:LVS) }\end{array}$ \\
\hline $27.6 \mathrm{kV}$ & $1-2 \mathrm{MW}$ & $\begin{array}{l}\text { Gnd-wye : Delta } \\
\text { Delta : Gnd-wye } \\
\text { Gnd-wye : Gnd-wye }\end{array}$ \\
\hline $27.6 / 12 / 8 \mathrm{kV}$ & $200 \mathrm{~kW}-1 \mathrm{MW}$ & $\begin{array}{l}\text { Gnd-wye : Gnd-wye } \\
\text { Gnd-wye : Delta } \\
\text { Delta : Gnd-wye }\end{array}$ \\
\hline $27.6 / 12 / 8 / 4 \mathrm{kV}$ & $50 \mathrm{~kW}-200 \mathrm{~kW}$ & Gnd-wye : Gnd-wye \\
\hline $27.6 / 12 / 8 / 4 \mathrm{kV}$ & $10 \mathrm{~kW}-50 \mathrm{~kW}$ & Gnd-wye : Gnd-wye \\
\hline
\end{tabular}

The primary substation feeders coming out of the power transformer have the general connections in either Delta winding or the Wye connection with grounding . the ground reference to the distribution system is obtained from the distribution transformers. A three phase four wire distribution system is generally installed in the secondary distribution side and the transformer associated is chosen accordingly. If the distribution system is of single phase, then the transformer having a center tap is chosen to provide the neutral connections.

\section{CONTROLLER}

Design of PID Controller:

The difference between actual and the set value is to be inimized so that the process variable is as per requirements system. For this, a proportional-integral-derivative perational amplifiers. Continuous use is required for the system since an error is expected to happen due to the changes in the system behavior according to the input variables or changes in the set values. Parameters such as the rise time and peak overshoots are to be minimized to the controller gains is necessary in real-time.

\# The proportional controller gain is associated with the magnitude shift of the output signal based on the input error magnitude. For example, if the error value is large, then, the output signal is multiplied by the gain value so that the output is increased proportionally.

\# the integral controller accumulates input values over a period and hence introduces a delay in the system response. As the input value samples and amplitudes increase, the output response also changes accordingly.

\# based on the derivative of error signal, i.e the slope of the sample causes the output to change.

The block diagram representation of a PID controller is given in Figure 3.

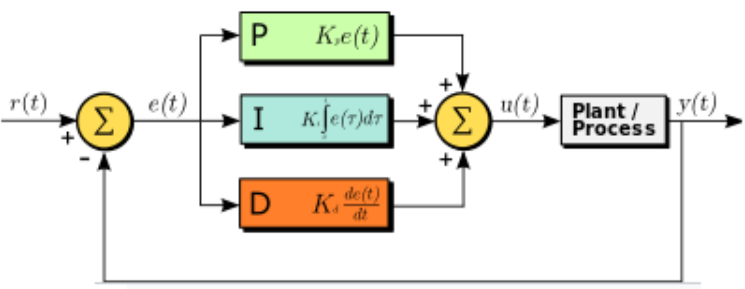

Fig 3: Block diagram of PID controller

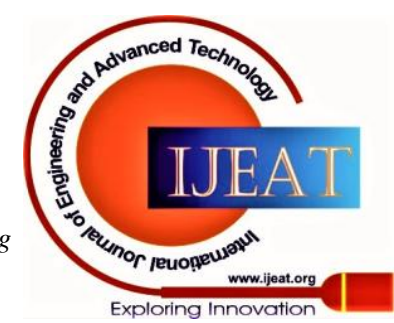




\section{Design of FLC controller:}

A fuzzy logic controller is introduced in the paper. A FLC is typically either based on Mamdani or Takagi Sugeno methods of relating the crisp input values to the output parameters. In this paper, FLC is used to predict the sizing of DGs that are to be placed in the primary and secondary distribution feeders so that the reserve capacity of the system is increased and maintained to enhance reliability. It also decreases power losses in the transmission system as the load value changes, unbalance of voltages, and imbalances on the apparent power. The takagi sugino type of controller is employed to site the location of DGs based on the output power produced, surviving index, and the nodal distance from the substations.

The expert system based on fuzzy-logic-controller is tested using the MATLAB software. Fuzzy logic toolbox is used and simscape simPowersystem platform is used to execute the multi-rule-based FLC system.

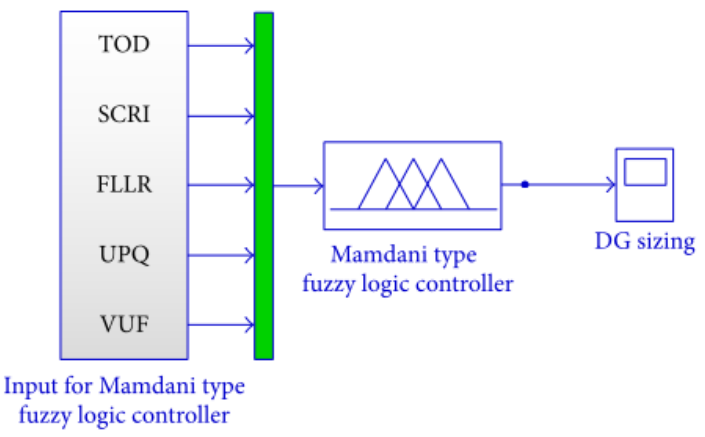

Fig 4: FLC - Mamdani type

Mamdani type FLC as shown in figure 4, uses the MIN-MAX aggregation and defuzzification as standard settings. The Sugeno type parameters remains the same for defuzzification method proposed as in the Mamdani type. In the process of fuzzification, these inputs are converted into crisp form in accordance with the membership functions associated. Triangle membership function is adopted for medium value FLLR, UPQ, and VUF, whereas membership functions of trapezoidal are considered for the low and high of the above three variables. A set of 15 fuzzy rules, which involve the rules based on all combinations possible for calculating the size of DG after the fuzzification process is applied to get the output.

\section{Design of Adaptive controller:}

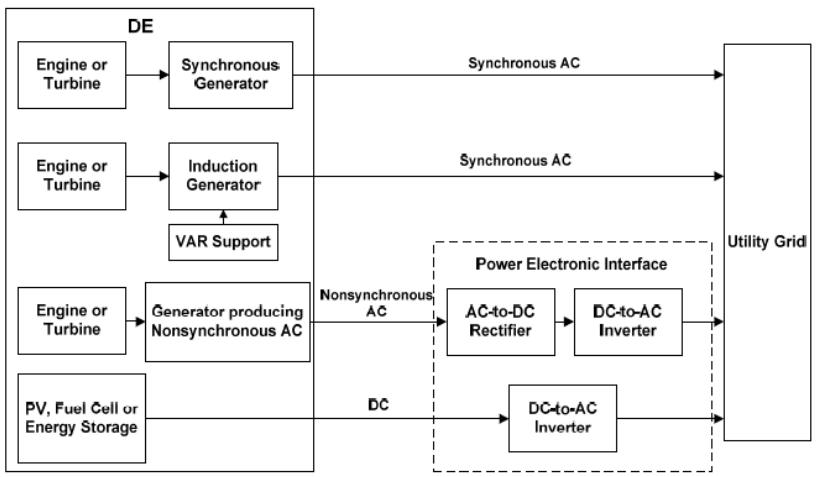

Fig 5: Different DGs connected to the utility grid
If $K_{P}$ and $K_{I}$ are not selected properly, the response of the system shall be poor and may not be reliable particularly at extreme conditions. The decision made by the controller will cause instability in the system operation and lead to failure. So preventing a poor system response and optimizing the response (speed) are desired from the design of the PI controller perspective. Setting the goal for creating an hybrid combination of adaptive PI design that can be dynamically adjusting the $K_{P}$ and $K_{I}$ parameters in real-time system is required. The proposed adaptive PI control method, inspired by the generic adaptive control method in [9], consists of three procedures:

- $\quad$ Determine the DC source voltage of the DE;

- $\quad$ Set the initial values, $K_{P}$ and $K_{I}$ parameters.

- Self-learning capability to adjust $K_{P}$ and $K_{I}$ dynamically.

The controller parameters with a fixed $K_{P}$ and $K_{I}$ may not always reach the desired and acceptable output response in power systems where the system load and other conditions are changing constantly. The controller parameters must be adjusted according to real-time system boundaries. Typically chosen initial Lower gain parameters, $K_{P}$ and/or $K_{I}$, so that they do not have any poor response and cause instability problems. Utilizing the voltage parameter as the input to the controller is implemented in this paper to tune $K_{P}$ and $K_{I}$ values. Elimination of an expensive and extensive centralized communications system is also needed in the system, since the parameters track locally defined ideal voltage response curve. The sampling rate of the sensor data is chosen to have high frequency. With the help of modern power electronics, we can ensure that the simulations and field testing are carried out hand in hand to implement adaptive voltage control. Figure 5 represents the DGs connected to utility grid.

\section{SIMULATION RESULTS}

\section{a. Protection by varying external faults like LG, LLG and LLLG faults by varying different controllers:}

The system without distributed generation is represented using a Matlab simulation as shown in fig. 6. A three-phase system is considered here with a combination of circuit breakers to simulate the fault environment and to analyze the response of the system. when the system goes into islanding mode, it is detected, and the breakers are operated accordingly based on PID controller is used in the system. the detailed modelling of the PID controller is shown in the figure 7. A three phase PLL is used to find out the angular frequency of the input voltage and current waves. The error is calculated with reference to the set values and is processed through the controller to get the control output signals.

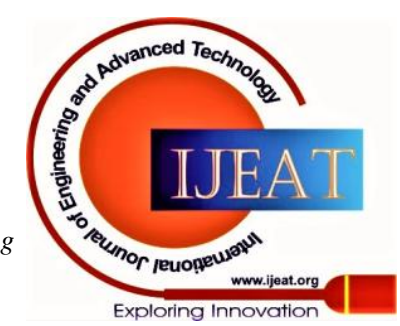




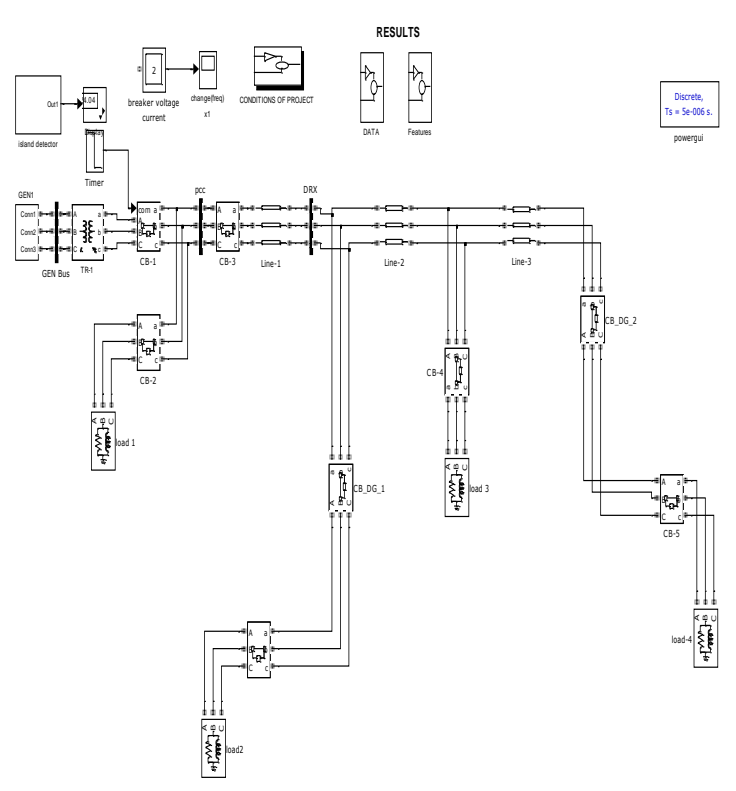

Fig 6: Simulation model with PID controller, Circuit breakers and without DG

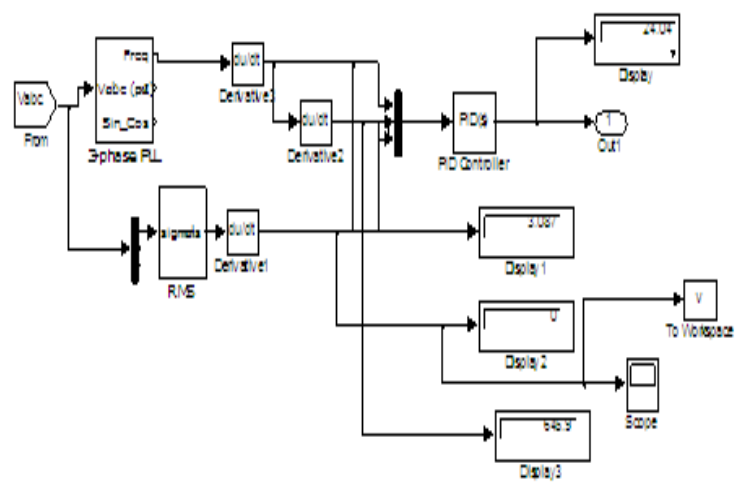

Fig 7: Subsystem of PID controller

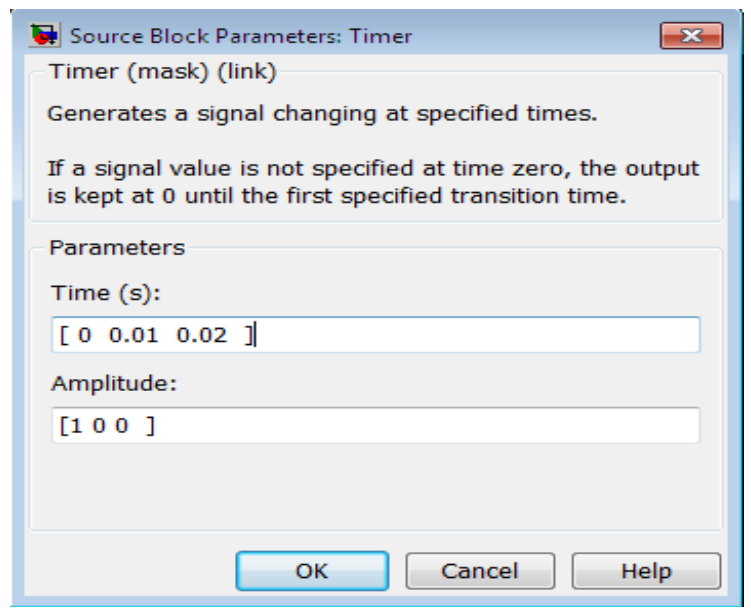

Fig 8: Circuit Breaker timing

The settings of the timer block are shown in fig.8 . This is set to have a frequency of $50 \mathrm{~Hz}$, indicated by the time period of $0.02 \mathrm{sec}$. This signal is applied to the circuit breaker shown in fig. 6.

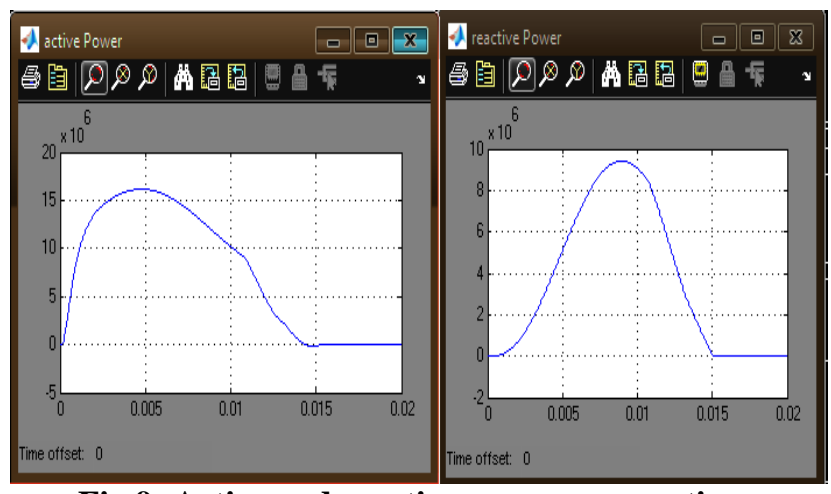

Fig 9: Active and reactive powers versus time

The active and reactive power that in the system is represented in fig. 9, indicating that at time $t=0.015 \mathrm{sec}$, when the breaker is closed, the values fall to zero. The subsystem of FLC controller is shown in fig. 10. This can be correlated to fig. 7 and noticeably the PID controller there is replaced by the FLC controller. The modified active and reactive powers is shown in fig. 11 .

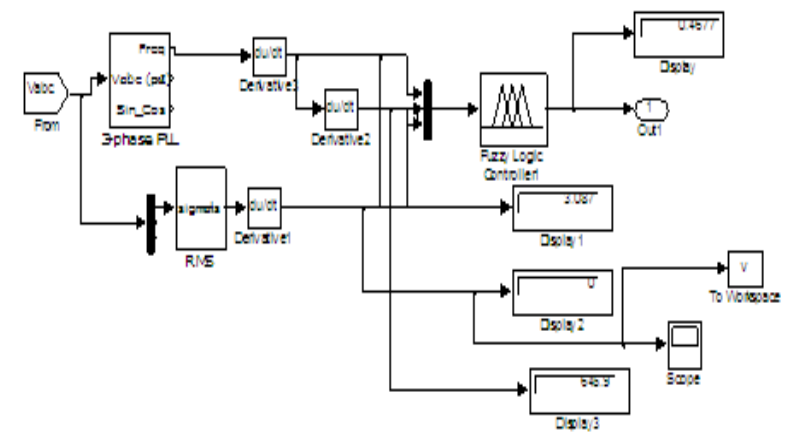

Fig 10: Subsystem of FLC controller

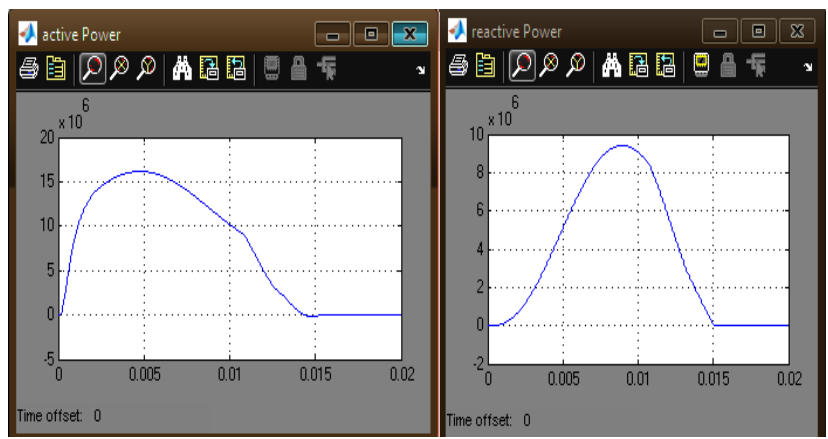

Fig 11: Active and reactive powers versus time

The active and reactive power shown in fig 11 represent the MW and MVAR flow in the system. The system simulation model with PID controller without the inclusion of DG is shown in figure 12 .

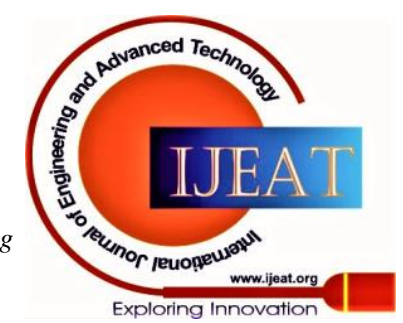



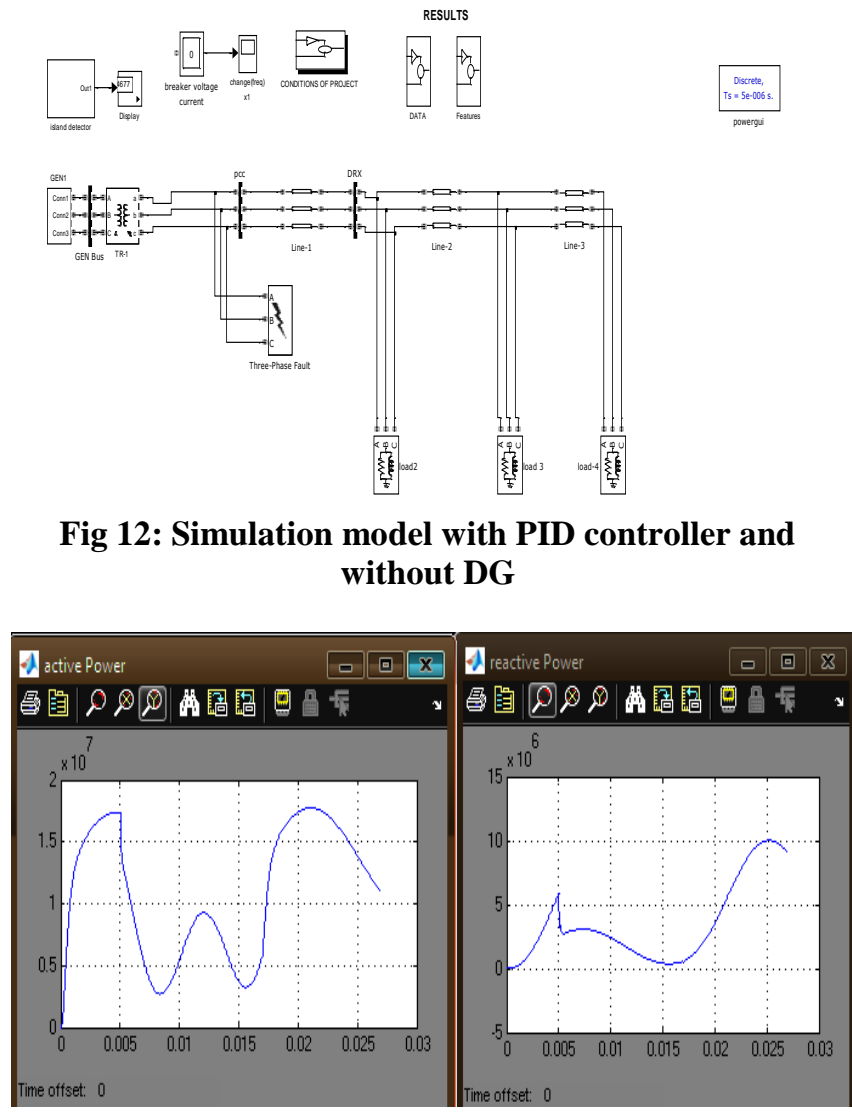

Fig 13: LG fault

When the LG fault is imposed on the system, the response is as shown in the figure 13 . The real and reactive powers in the system are shown here. Similarly, the LLG fault response is shown in the figure 14 . The variations are within the limits and the variation is according to the after-fault effects on the system. the LLLG fault response is shown in fig. 15. In the next phase, the adaptive controller is implemented as shown in figure 16. A Matlab code is written for the implementation of this adaptive controller gains of the system. this is shown in figure 17.

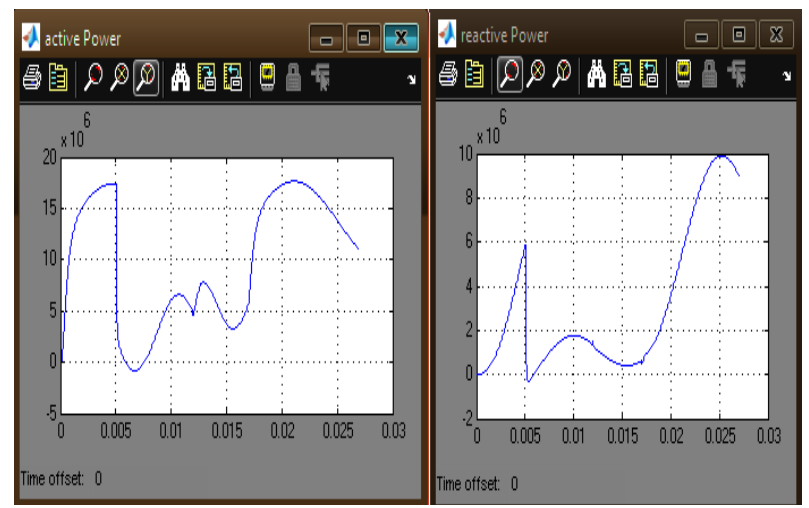

Fig 14: LLG fault

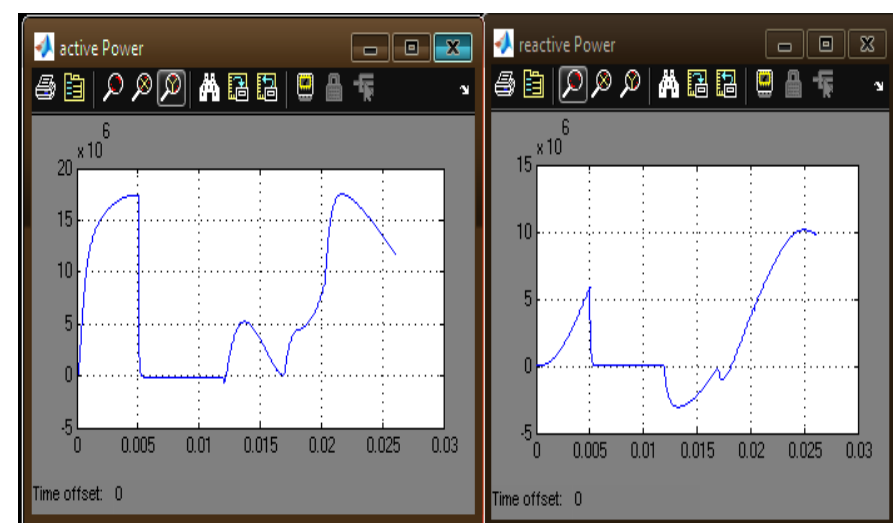

Fig 15: LLG fault

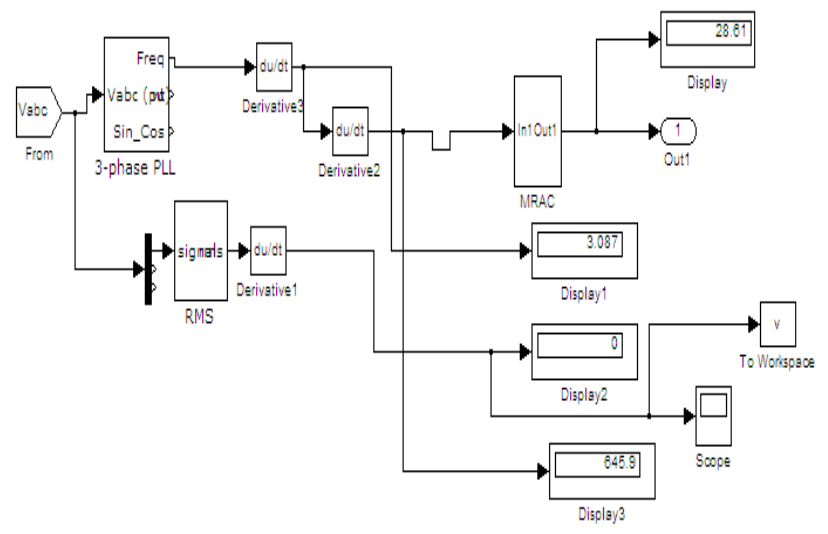

Fig 16: With adaptive controller

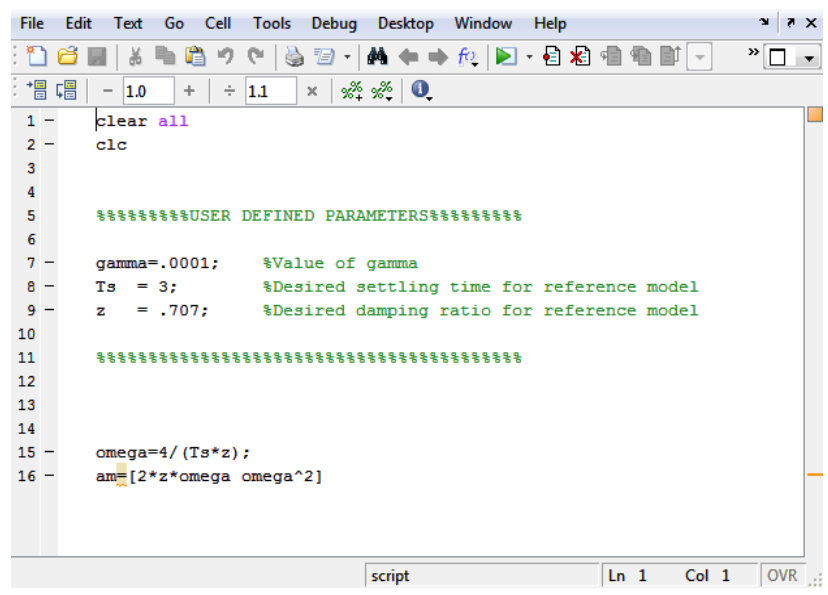

Fig 17: M-file program

After implementation of the LG, LLG, and LLLG faults on the system with adaptive controller in action, the responses of the active and reactive power flows are as shown in figures 18,19 and 20 respectively. It can be seen that there is a significant improvement in the response of the system.

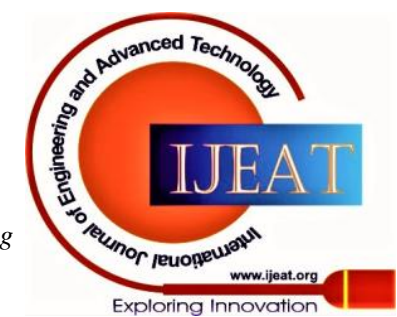




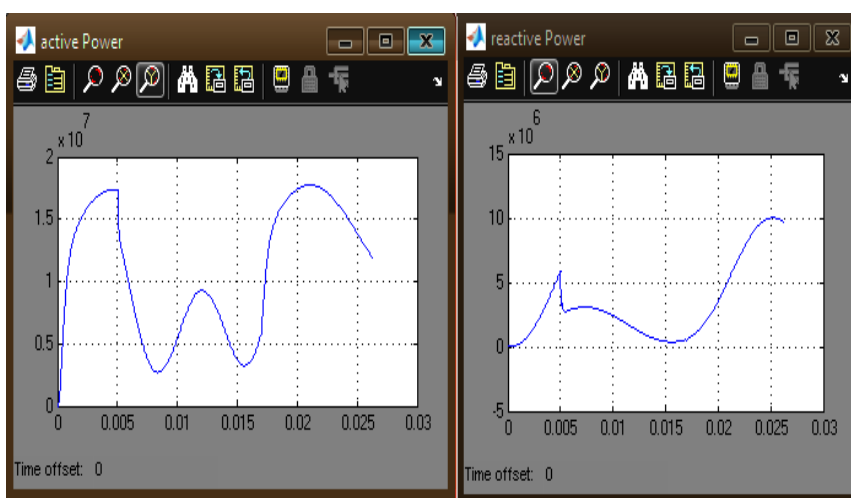

Fig 18: LG fault

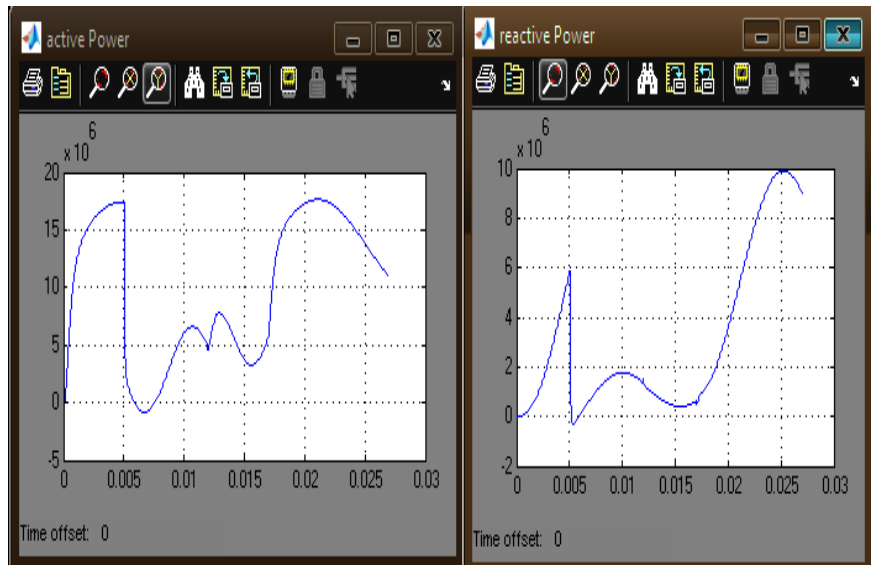

Fig 19: LLG fault

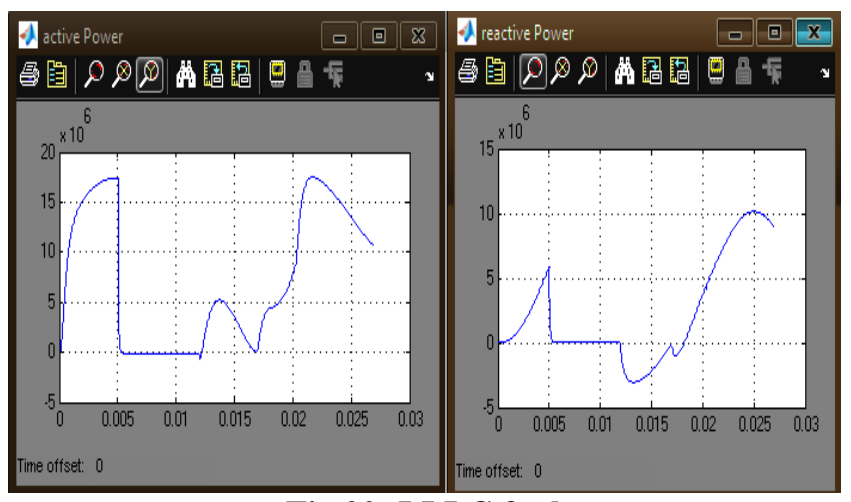

Fig 20: LLLG fault

Table 3: Comparison table of power variation in fault period i.e between 0.05 to $0.1 \mathrm{sec}$

\begin{tabular}{|c|l|l|l|l|l|l|}
\hline $\begin{array}{c}\text { Without } \\
\text { DG and } \\
\text { different } \\
\text { controllers }\end{array}$ & LG & LLG & LLLG & LG & LLG & LLLG \\
\cline { 2 - 7 } & 0.5 & 3.5 & 2.5 & 2.2 & 1.3 & -1.25 \\
\hline $\begin{array}{c}\text { PID } \\
\text { controller }\end{array}$ & 0.6 & 3.6 & 2.5 & 1.7 & 0.9 & -1.3 \\
\hline $\begin{array}{c}\text { FLC } \\
\text { controller }\end{array}$ & 0.5 & 3.65 & 2.5 & 1.5 & 0.95 & -1.6 \\
\hline $\begin{array}{c}\text { Adaptive } \\
\text { controller }\end{array}$ & 3.25 & 3.65 & & & &
\end{tabular}

Table 4: Comparison table of power variation in fault period i.e between 0.05 to $0.1 \mathrm{sec}$

\begin{tabular}{|c|c|c|c|c|c|c|}
\hline \multirow{2}{*}{$\begin{array}{c}\text { With DG } \\
\text { and } \\
\text { different } \\
\text { controllers }\end{array}$} & \multicolumn{3}{|c|}{ Active power } & \multicolumn{3}{|c|}{ Reactive power } \\
\cline { 2 - 6 } & LLG & LLLG & LG & LLG & LLLG \\
\hline
\end{tabular}

\begin{tabular}{|c|l|l|l|l|l|l|}
\hline $\begin{array}{c}\text { PID } \\
\text { controller }\end{array}$ & 0.2 & 3.5 & 2.56 & 2.22 & 1.13 & -0.25 \\
\hline $\begin{array}{c}\text { FLC } \\
\text { controller }\end{array}$ & 0.45 & 3.45 & 2.25 & 1.71 & 0.8 & -1.1 \\
\hline $\begin{array}{c}\text { Adaptive } \\
\text { controller }\end{array}$ & 3.15 & 3.5 & 2.51 & 1.55 & 0.75 & -1.4 \\
\hline
\end{tabular}

Tables 3 and 4 indicate the response times without DG and different controllers, PID controller, FLC controller and Adaptive controller. The response times have significantly reduced with the inclusion of DGs and with the implementation of Adaptive controller.

\section{CONLUSIONS}

Protection is a very important aspect, whenever a change is proposed in the system configuration. Introduction of DGs in the system pose new problems though they are introduced to sort out the stated problems of fault protection and power flow control. The adaptive control methodology implemented in the paper has resulted in a improved response of the system to the faults that happen in the system. The system modelled in MATLAB - Simulink environment and the program implementation of adaptive control has shown that the power flow is controlled and is within the limits of the standards. The efficient working of DGs such as wind turbines, microturbines, solar, PEMFC and SOFC units placed in the system is evident from the results obtained and presented in the paper during normal and faulty conditions. Coordinated operation of the DGs observed so that the overall active and reactive power is shared by the generators. The distance between the source and load point also has a significant effect on the overall response of the DGs.

\section{REFERENCES}

1. L.L. Lai and T.F. Chan, "Distributed Generation, Induction and Permanent Magnet Generators", John Willey and Sons, West Sussex, 2007.

2. Y. Lei, A.Mullane, G.Lightbody, and R.Yacamini, Modeling of the Wind Turbine With a Doubly Fed Induction Generator for Grid Integration Studies",IEEE Transactions on Energy Conversion, Vol.21(1), pp.257-264, 2006.

3. D. Kusdiana, "Real conditions in Indonesia Energy Needs and Alternative Sources of Renewable Energy", Presented at the Seminar of Renewable Energy, Directorate General of Electricity and Energy Utilization, Department of Energy and Mineral Resources, 3 Dec. 2008, Bogor, Indonesia.

4. A. Tapia, G. Tapia, J. X. Ostolaza, and J. R. Saenz, "Modeling and control of a wind turbine driven doubly fed induction generator", IEEE Transactions on Energy Conversion, Vol.18, pp. 194-204, 2003.

5. K.S.V. Phani Kumar, S. Venkateshwarlu, "Impact of distance on the harmonic active power and energy metering at the load", International journal of Advances in Power Systems and Energy Management, Lecture Notes in Electrical Engineering, Springer.Vol-436, pp 637-645, Nov- 2017.

6. L. Mihet-Popa and F. Blaabrierg, "Wind Turbine Generator Modeling and Simulation Where Rotational Speed is the ontrolled Variable", IEEE Transactions on Industry Applications, Vol. 40, No.1, Jan./Feb. 2004.

7. D. M. Chahyal, M. N. Kalgunde and A. A. Kalage, "A study on protection issues in presence of distributed generation," 2017 International Conference on Algorithms, Methodology, Models and Applications in Emerging Technologies (ICAMMAET), Chennai, 2017, pp. 1-4

8. KSVP Kumar, K Deepika, S Venkateshwarlu, "Regulation of Frequency and Load Flow Study in a Multi-Area Power System Under Contingencies with the Inclusion of Wind-Generation", CVR Journal of Science and Technology vol-14, pp 27-31.

Published By:

Blue Eyes Intelligence Engineering and Sciences Publication

(C) Copyright: All rights reserved.

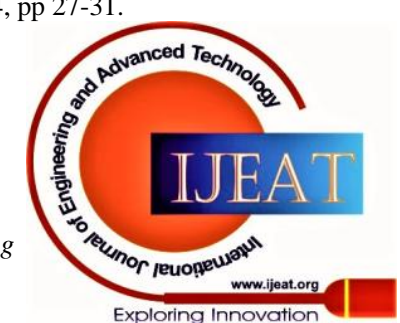


9. R. Syahputra, I. Robandi, and M. Ashari, "Reconfiguration of Distribution Network with DG Using Fuzzy Multi-objective Method", International Conference on Innovation, Management and Technology Research (ICIMTR), May 21-22, 2012, Melacca, Malaysia. 